\title{
TYPE LOCALITIES OF THE BADLANDS OLD WORLD SWALLOWTAIL IN ALBERTA
}

NORBERT G. KONDLA, Parks Division, Alberta Recreation and Parks, Rimbey, Alberta. TOC 2J0

Type specimens are important for taxonomic study because they represent the original concept of the organism to which a name was applied. Similarly the collection locations of type material are important because they indicate where persons doing subsequent study can find specimens representative of the taxon being studied.

The Badlands Old World Swallowtail (Papilio machaon dodi) was described by McDunnough primarily on the basis of specimens collected along the Red Deer River in Alberta. ${ }^{2}$ The original description was vague on the collection localities of the type material.

The holotype and paratypes were collected by F. H. Wolley-Dod along with Red Deer River "50 miles NE of Gleichen" according to McDunnough. ${ }^{2}$ Wolley-Dod's publications were vague on the exact location of his collections here and subsequent authors often erroneously assigned much of the pertinent material simply to Gleichen. Bird and Harper assigned Dorothy as the place where Wolley-Dod collected the Badlands Old World Swallowtail.' Prior to publication of Bird and Harper's paper, I had independently arrived at the same conclusion. Therefore, the type locality of the Badlands Old World Swallowtail is now fixed as Dorothy, Alberta.

There remains now to clarify the location of the allotype specimen collected by $\mathrm{C}$. H. Young on 8 July 1917. McDunnough stated that the allotype was collected "in the same general region" (as the holotype).
However, this is not correct because Young's field itinerary as published by Taverner shows that the allotype was. collected along the Red Deer River near Nevis, about $100 \mathrm{~km} \mathrm{NW}$ of Drumheller. $^{3}$

The machaon complex of swallowtails (in Alberta represented by the species names zelicaon, machaon, and bairdii) has received considerable attention by taxonomists but there are still more questions than answers. Specimens with intermediate characters and variation of 'black' phenotypes make it difficult to pigeonhole many specimens. Distribution and ecology are also poorly documented in the literature Research presently underway by $F$ Sperling at the University of Alberta wil surely help to clarify this interesting group of swallowtails.

'BIRD, C. D. and A. M. HARPER 1980. F. Wolley-Dod, Alberta's leading pionee lepidopterist; Alberta Naturalist 10:40 55.

${ }^{2}$ MCDUNNOUGH, J. H. 1939. A new race Papilio belonging to the machaon com plex. Canadian Entomologist 71:216 217.

${ }^{3}$ TAVERNER, P. A. 1919. The birds of th Red Deer River, Alberta. Auk 35:1-2 248-265.

EDITOR'S NOTE: The type specimen holotype is the individual from which is mac the original taxonomic description of species. Paratype specimens are addition specimens cited in the original taxonom description. An allotype specimen is paratype of the opposite sex to the holotyp and is designated in the original descriptio 